\title{
Expressão de galectina-3 e beta-catenina em lesões pré-malignas e carcinomatosas de língua de camundongos
}

\section{Galectin-3 and beta-catenin expression in premalignant and carcinomatous lesions in tongue of mice}

Juliana Moreira de Almeida Sant'ana'; Daniella Fernandes Mendonçą ; Roger Chammas ${ }^{3}$; Suely Nonogaki ; Sérgio Vitorino Cardoso5; Adriano Mota Loyola ${ }^{6}$; Paulo Rogério de Faria ${ }^{7}$

uniter
Carcinogênese
4NQO
Galectina-3
Beta-catenina
Língua
Camundongos

\section{resumo}

Introdução: A galectina-3 (GAL3) apresenta importantes papéis na biologia tumoral e recentemente foi mostrada a sua participação na via de sinalização Wnt, translocando a beta-catenina para o núcleo. Expressão alterada de GAL3 e beta-catenina tem sido descrita em cânceres, mas não há estudos avaliando a expressão de ambas em displasias e carcinomas desenvolvidos em modelos de carcinogênese de língua. Objetivos: Estudar a expressão de GAL3 e beta-catenina em lesões displásicas e carcinomas induzidos experimentalmente em língua de camundongos. Material e métodos: Vinte camundongos C57BL/6 machos foram desafiados com $4 \mathrm{NQO}$ na água de beber por 16 semanas e sacrificados na semana $16 \mathrm{e}$ 32. Após o sacrifício, as línguas foram removidas, processadas, coradas por hematoxilina e eosina (HE) para detecção de displasias e carcinomas. Ensaio imuno-histoquímico foi realizado para determinar o índice de positividade para GAL3 e beta-catenina nessas lesões, bem como uma correlação entre elas em carcinomas. Resultados: $\mathrm{O}$ número de camundongos afetados por carcinoma aumentou entre as semanas 16 e 32 (22,2\% vs. $88,9 \%)$ e o de displasia diminuiu $(66,7 \%$ vs. $11,1 \%)$. Um aumento de células positivas para beta-catenina não membranosa e GAL3 citoplasmática foi observado nas displasias e nos carcinomas, mas essa diferença não foi estatisticamente significativa. No entanto, um aumento estatisticamente significativo de GAL3 nuclear foi observado na evolução de displasia para carcinoma $(p=0,04)$. Nenhuma correlação foi encontrada entre beta-catenina e GAL3. Conclusão: Tanto nas displasias quanto nos carcinomas a via de sinalização Wnt está ativa, e o aumento de GAL3 nuclear nos carcinomas sugere um papel na transformação maligna do epitélio lingual.

\section{abstract}

Introduction: Galectin-3 plays pivotal role in tumor biology and its participation in Wnt signaling pathway translocating beta-catenin into the nucleus has been recently demonstrated. Altered galectin-3 and betacatenin expressions have been described in different tumors, however, there are no studies evaluating their expression in dysplasias and carcinomas induced in carcinogenic tongue models. Objectives: To study galectin-3 and beta-catenin expressions in dysplasias and carcinomas experimentally induced in mouse tongue. Methods: Twenty C57BI/6 male mice were treated with 4NQO in their drinking water for 16 weeks and sacrificed at weeks 16 and 32. Tongues were removed, routinely processed, and stained with hematoxylin and eosin to detect dysplasias and carcinomas. An immunohistochemical assay was performed to determine the level of positivity for galectin-3 and beta-catenin in these lesions as well as their correlation in carcinomas. Results: The number of mice affected by carcinomas increased from week 16 to week $32(22.2 \%$ vs. 88.9\%) and the number affected by dysplasias decreased (66.7\% vs. $11.1 \%)$. There was an increase in non-membranous beta-catenin-and cytoplasmic galectin-3-positive cells in dysplasias and carcinomas, although this difference was not statiscally significant. Nonetheless, there was a significant increase of nuclear galectin-3-positive cells in the evolution from dysplasia to carcinoma $(\mathrm{p}=0.04)$. There was no correlation between beta-catenin and galectin-3. Conclusion: Wnt signaling pathway is active in both dysplasias and carcinomas and the increase of nuclear galectin-3-positive cells in carcinomas suggests its influence on malignant transformation in the tongue epithelium.

\section{key words}

Oral carcinogenesis

$4 N Q O$

Galectin-3

Beta-catenin

Tongue

Mice

1. Graduada em Enfermagem pela Faculdade de Medicina da Universidade Federal de Uberlândia (FAMED-UFU).

2. Graduada em Enfermagem pela FAMED-UFU.

3. Doutor em Ciências Biológicas (Bioquímica); professor titular da Faculdade de Medicina da Universidade de São Paulo (FMUSP).

4. Graduada em Farmácia e Química; pesquisadora científica do Instituto Adolfo Lutz, Centro de Patologia, Núcleo de Patologia Quantitativa e Molecular.

5. Doutor em Patologia Bucal; professor adjunto II da Faculdade de Odontologia da Universidade Federal de Uberlândia (FOUFU).

6. Doutor em Patologia Bucal; professor associado da FOUFU.

7. Doutor em Ciências (Patologia Geral); professor adjunto I do Instituto de Ciências Biomédicas da UFU. 


\section{Introdução}

Com cerca de 390 mil novos casos diagnosticados anualmente em todo o mundo, o câncer de boca enquadra-se entre os dez mais frequentes tumores malignos que acometem o ser humano ${ }^{(8,23,28)}$. O aparecimento desse tipo de câncer está relacionado com o uso abusivo de tabaco e bebidas alcoólicas e, na maioria dos casos, apresenta prognóstico ruim e alta taxa de mortalidade ${ }^{(7,17)}$. Embora o desenvolvimento do câncer bucal seja usualmente precedido de um estágio pré-maligno, o mecanismo molecular envolvido nessa transformação é desconhecido ${ }^{(11)}$. Diante desse quadro, estudos voltados a desvendar os mecanismos moleculares para esse tipo especial de neoplasia são imprescindíveis para o melhor controle da doença. Para isso, modelos experimentais com animais desafiados com potentes carcinógenos têm sido considerados padrão-ouro no estudo da carcinogênese bucal e no papel de proteínas específicas no desenvolvimento dessas doenças.

As galectinas têm emergindo como promissoras na compreensão de inúmeras doenças, incluindo o câncer. Galectinas são lectinas de animais ligantes de resíduos betagalactosídeos por meio de um domínio de reconhecimento de carboidrato de cerca de 130 aminoácidos altamente conservado na natureza ${ }^{(20,21,31)}$. Dos 15 tipos de galectinas reconhecidas, a galectina-3 (GAL3), uma proteína de 30 a $35 \mathrm{kDa}$, é uma das mais estudadas ${ }^{(21,25,31)}$. A GAL3 está envolvida em diferentes processos fisiológicos e patológicos, incluindo aqueles associados ao câncer, como transformação neoplásica, progressão tumoral e metástase ${ }^{(2-4)}$. Vários estudos têm analisado a sua expressão em diferentes tumores, mas os resultados alcançados são ainda contraditórios. Enquanto em tumores de tireoide e estômago a expressão de GAL3 está aumentada, os tumores de pele, mama e ovário exibem baixa expressão(21). Similarmente, a localização intracelular de GAL3 também parece estar associada à progressão tumoral ${ }^{(14)}$. Em tumores de língua, um aumento da GAL3 citoplasmática está relacionado com progressão tumoral e menor taxa de sobrevida ${ }^{(17)}$. Contudo, os resultados da literatura para tumores de cabeça e pescoço são ainda muito contraditórios e pouco se conhece sobre o papel da GAL3 no desenvolvimento dessas neoplasias malignas.

Assim como a GAL3, proteínas da via de sinalização Wnt (adenomatous poliposis coli [APC], beta-catenina, axina e quinase de glicogênio sintase-3beta [gsk-3ß]) contribuem para o desenvolvimento de neoplasias malignas, como carcinoma hepatocelular, meduloblastoma, melanoma, próstata, pâncreas, de cólon e de boca ${ }^{(10,14,33,39)}$. Estudos recentes têm mostrado que a via de sinalização Wnt está alterada durante a tumorigênese, o que parece ser reflexo das diferentes funções exercidas pela beta-catenina, bem como por sua localização intracelular( ${ }^{(33,39)}$. Recentemente, foi demonstrado que a GAL3 participa da via de sinalização Wnt interagindo com a beta-catenina para promover a ativação transcricional dos genes da ciclina D1 e c-Myc ${ }^{(35,36)}$. Contudo, estudos demonstrando a participação de GAL3 e da beta-catenina no desenvolvimento do carcinoma epidermoide de boca a partir de modelos experimentais não têm sido descritos até o presente momento.

O objetivo deste trabalho foi estudar, em um modelo experimental de carcinogênese bucal, a expressão por imuno-histoquímica de GAL3 e beta-catenina em displasias e carcinomas desenvolvidos em língua de camundongos desafiados com o carcinógeno 4-nitroquinolona-1-oxido (4NQO). Além disso, procuramos com este estudo mostrar uma possível participação da GAL3 na via de sinalização Wnt por meio de uma análise de correlação entre ela e a beta-catenina nas amostras de carcinomas.

\section{Material e métodos}

A execução deste trabalho foi aprovada pela Comissão de Ética no Uso de Animais da Universidade Federal de Uberlândia (UFU) sob o protocolo n $038 / 09$.

\section{Animais}

Vinte camundongos machos da linhagem C57BL/6, de 6 a 8 semanas de idade e pesando entre 20 e $23 \mathrm{~g}$, foram divididos em dois grupos: grupo $_{16}$ - sacrificados imediatamente após o término do tratamento com o $4 \mathrm{NQO}$ $(n=10)$; $_{\text {grupo }}$ - sacrificados 16 semanas após o término do tratamento com o 4NQO $(n=10)$. Todos os camundongos foram colocados em gaiolas de plástico forradas com serragem e mantidos à temperatura de $22^{\circ} \mathrm{C}$, ciclo claro/escuro de $12 \mathrm{~h} / 12 \mathrm{~h}$ e alimentados com ração específica ad libitum.

\section{Protocolo de experimentação}

O tratamento com o 4NQO foi embasado no protocolo descrito por Tang et al.(37) O carcinógeno 4NQO, diluído inicialmente em propilenoglicol $(5 \mathrm{mg} / \mathrm{ml})$ e depois em água filtrada até atingir a concentração final de $100 \mu \mathrm{g} / \mathrm{ml}$, foi administrado por um período máximo de 16 semanas. Durante todo o período de tratamento, a solução de 4NQO foi preparada e trocada semanalmente nos frascos de beber dos camundongos. Ao término da semana 16, o tratamento foi interrompido e os animais grupo ${ }_{16}$ foram imediatamente 
sacrificados, enquanto os camundongos do grupo ${ }_{32}$ passaram a beber apenas água filtrada por mais 16 semanas $\mathrm{e}$ depois sacrificados ao final desse período.

\section{Exame microscópico das línguas}

Após anestesia profunda com éter etílico, seguida de deslocamento cervical, os camundongos foram autopsiados e suas línguas removidas e imediatamente fixadas em formalina tamponada a 10\% por 24 horas. Após esse período, cada língua foi cortada transversalmente em cinco fragmentos, processada rotineiramente e incluída em parafina. Na presença de uma alteração em superfície lingual, procurou-se representar da melhor forma possível tal alteração para estudo microscópico, além de outros fragmentos da mesma língua. Para cada animal, um corte de $5 \mu \mathrm{m}$ de espessura foi corado por hematoxilina e eosina (HE) para análise microscópica. Os cinco fragmentos de cada língua foram analisados individualmente em microscópio de luz para diagnóstico das displasias e dos carcinomas. Para isso, foram utilizados os critérios estabelecidos por Lumerman et al. (24) e Barnes et al.(1), respectivamente. Além disso, quando duas ou mais áreas de uma mesma secção histológica exibiam alterações epiteliais distintas, isto é, displasia e carcinoma, aquela de maior grau foi usada para determinar a alteração patológica que o camundongo apresentava.

\section{Imuno-histoquímica}

As proteínas beta-catenina e GAL3 foram identificadas por imuno-histoquímica por meio do método estreptavidina-biotina-peroxidase. Cortes histológicos de $3 \mu \mathrm{m}$ de espessura foram previamente montados em lâminas silanizadas com organosilano (SIGMA Chemicol Co, St Louis, MO, USA). Após desparafinização e desidratação, seguiu-se a recuperação dos epitopos antigênicos em solução tampão de ácido etilenodiaminotetracético (EDTA), 1 mM, pH 8 em micro-ondas. Em seguida, realizou-se o bloqueio da peroxidase endógena com solução de $\mathrm{H}_{2} \mathrm{O}_{2}$ a $10 \mathrm{~V}$ e da biotina endógena (DAKO Co, Carpenteria, USA). Por fim, os cortes foram incubados com anticorpos primários antibetacatenina (clone H102, Santa Cruz Biotechnology, CA, USA), na titulação de 1:200, e anti-GAL3 (TIB 166, hibridoma, da American Type Culture Collection e gentilmente cedido pelo prof. Roger Chammas), na titulação de 1:30, overnight a $4^{\circ} \mathrm{C}$, em câmara úmida. Após lavagem em solução tampão fosfato-salino (PBS), deu-se a incubação com anticorpos secundários específicos para cada anticorpo primário. A revelação da reação foi feita com 3,3'-diaminobenzidina tetra-hidroclorido (DAKO Co, Carpenteria, USA) e os cortes contracorados com hematoxilina de Harris. Como controle positivo para beta-catenina e GAL3, utilizou-se amostra de tonsila palatina para cada reação. Para controle negativo das reações, os anticorpos primários foram substituídos pela solução diluente dos mesmos.

Uma análise quantitativa foi usada para avaliar a expressão de GAL3 e beta-catenina. Para isso, estabeleceu-se um índice de positividade para beta-catenina e GAL3 como sendo a relação entre o número de células marcadas e o número total de células contadas nas áreas de displasias e carcinomas; por fim, um índice médio de positividade foi estabelecido para cada lesão analisada. Foram consideradas positivo todas as células que apresentavam coloração marrom na microscopia de luz, sendo em núcleo e citoplasma para GAL3 e membrana e núcleo e/ou citoplasma para betacatenina. Para fins de contagem, foram obtidos campos microscópicos em aumento de 400x. Devido ao pequeno tamanho das lesões, todos os campos obtidos de cada lesão foram usados na contagem de células. Além disso, com base no duplo papel exercido pela beta-catenina na célula, considerou-se, para fins de contagem, sua localização em membrana (padrão membranoso, relacionado com sua função na adesão celular) e núcleo/citoplasma (padrão não membranoso, relacionado com sua participação na via de sinalização Wnt). De forma semelhante, como a GAL3 exerce diferentes funções dependendo de sua localização intracelular, considerou-se, para fins de contagem, sua presença em núcleo e citoplasma separadamente.

\section{Análise estatística}

Para avaliar os índices médios de positividade de betacatenina não membranosa/membranosa e GAL3 nuclear/ citoplasmática entre displasias e carcinomas, utilizou-se o teste não paramétrico de Mann-Whitney. Para determinar se a expressão de GAL3 está associada à ativação da via de sinalização Wnt, procurou-se estabelecer uma correlação entre beta-catenina não membranosa/membranosa e GAL3 nuclear/citoplasmática nos carcinomas. Para isso, utilizouse o teste de correlação de Spearman. Os valores foram expressos na forma de médias \pm desvio padrão; $p<0,05$ foi considerado estatisticamente significativo.

\section{Resultados}

Dois camundongos morreram ao final do experimento, sendo um da semana 16 e outro da semana 32 , contudo a causa mortis não foi determinada. 


\section{Análise microscópica}

De acordo com a Figura 1, a frequência de carcinomas após o tratamento com 4NQO aumentou entre as semanas 16 e 32 , com $88,9 \%$ dos camundongos da semana 32 acometidos por essa lesão (Figura 1). Diferente disso, a incidência de displasia reduziu no mesmo período, passando de $66,7 \%$ para $11,1 \%$ entre as semanas $16 \mathrm{e}$ 32 , respectivamente. Todos os carcinomas diagnosticados histopatologicamente foram classificados como bem diferenciados, e displasias de diferentes graus também foram observadas nas amostras analisadas.

\section{Imuno-histoquímica}

A Figura 1 mostra o padrão de marcação observado para beta-catenina e galectina-3 em displasias e carcinomas.
Nas displasias, o índice médio de positividade para betacatenina não membranosa foi maior do que em relação à beta-catenina membranosa ( $48 \pm 24,9 \%$ e $4,3 \pm 6,6 \%$, respectivamente). De modo parecido, embora um pouco maior, o índice médio de positividade nos carcinomas para beta-catenina não membranosa e membranosa foi de 58,7 \pm $24,9 \%$ e $7,7 \pm 6,8 \%$, respectivamente (Figura 2). Contudo, nenhuma diferença estatisticamente significativa foi alcançada com esses resultados, exceto na análise intragrupo. Diferente disso, um aumento estatisticamente significativo no índice médio de positividade para GAL3 nuclear foi observado na evolução das displasias para carcinomas $(9 \pm$ $6,9 \%$ e $15,7 \pm 8,1 \%$, respectivamente; $p=0,04$ ), indicando um possível papel na transformação maligna quando acumulada nesse compartimento celular. Por outro lado, nenhuma diferença significativa foi obtida entre displasias e

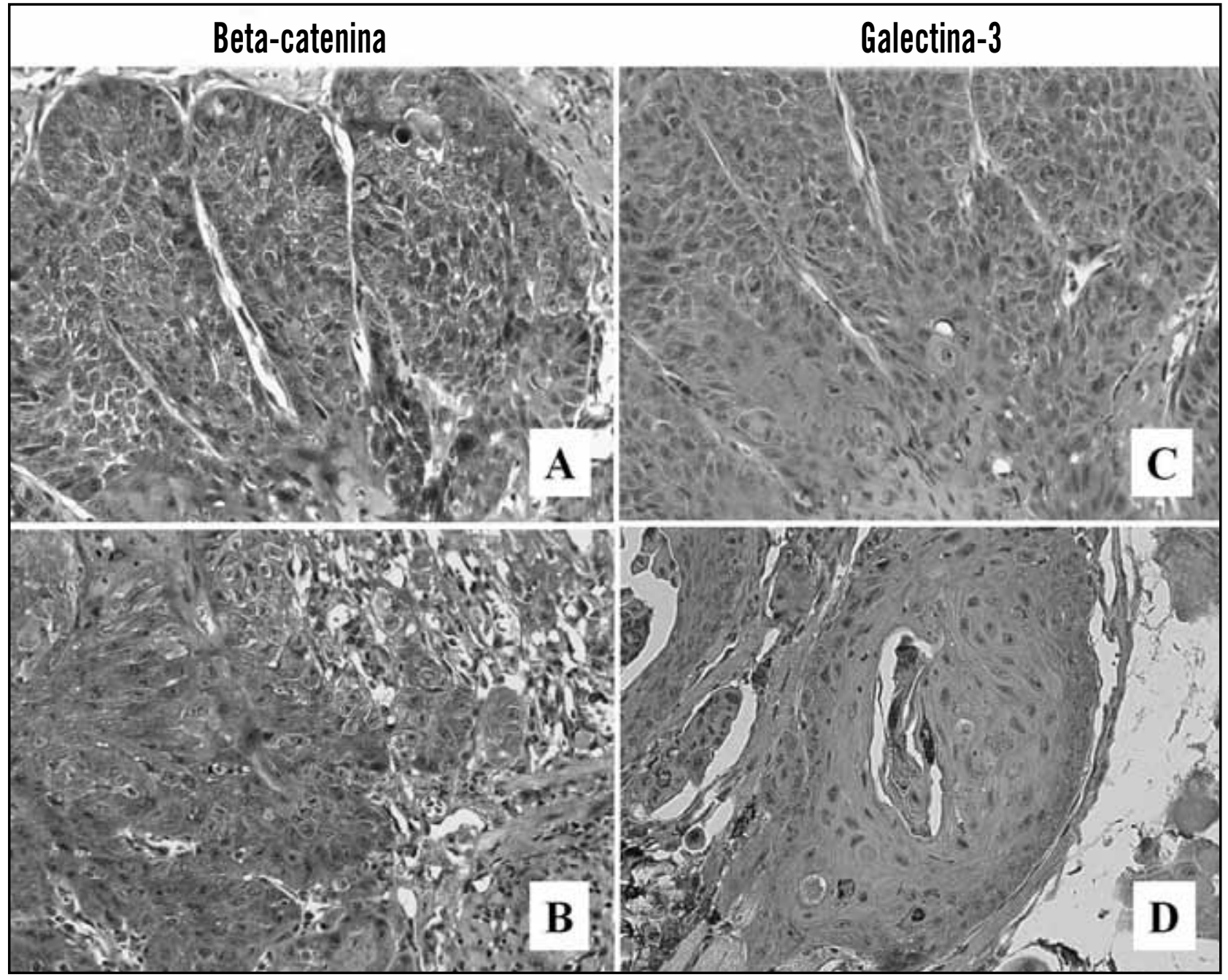

Figura 1 - Padrão de expressão imuno-histoquímica para beta-catenina e galectina-3. (A) Expressão de beta-catenina em lesão displásica mostrando predominância de marcação não membranosa (aumento de 400x); (B) expressão de beta-catenina em carcinoma mostrando a marcação predominante de beta-catenina não membranosa (aumento de 400x); (C) expressão de GAL3 em displasia com células exibindo marcação em citoplasma e núcleo (aumento de 400x); (D) expressão de GAL3 em carcinoma mostrando marcação nuclear de GAL3 nas células tumorais (aumento de 400x)

GAL3: galectina-3. 


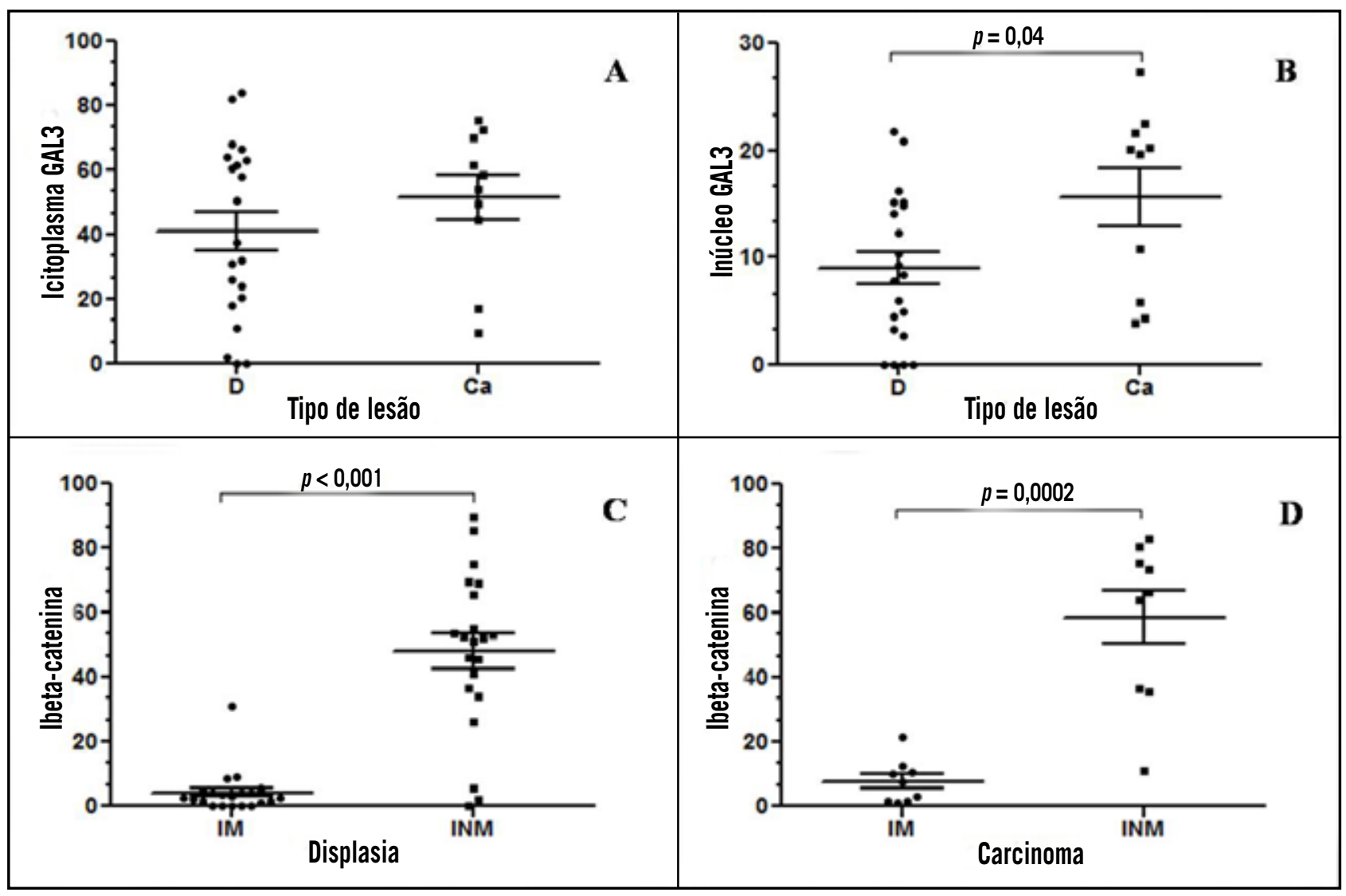

Figura 2 - Índice de positividade média para GAL3 e beta-catenina em displasias e carcinomas de camundongos. (A) Índice de positividade para GAL3 citoplasmática entre displasias e carcinomas; (B) índice de positividade para GAL3 nuclear entre displasias e carcinomas; (C) índice de positividade para beta-catenina não membranosa e membranosa nas displasias; (D) índice de positividade para beta-catenina não membranosa e membranosa nos carcinomas

Icitoplasma: índice de positividade citoplasmática; Inúcleo: índice de positividade nuclear; Ibeta-catenina: índice de positividade para beta-catenina; GAL3: galectina-3; D: displasia; Ca: carcinoma; IM: índice membranoso; INM: índice não membranoso.

carcinomas no que diz respeito a GAL3 citoplasmática $(41,1 \pm$ $27 \%$ e $51,4 \pm 21,2 \%$, respectivamente) (Figura 2). Diferentemente do esperado, nenhuma correlação foi encontrada entre beta-catenina não membranosa/membranosa e GAL3 nuclear/citoplasmática nos carcinomas $(p>0,05)$.

\section{Discussão}

O objetivo deste estudo foi avaliar a expressão de GAL3 e beta-catenina em lesões displásicas e carcinomas obtidos a partir de um modelo bem estabelecido de carcinogênese bucal em camundongos. Os nossos achados mostraram que a transformação maligna do epitélio lingual está associada ao aumento de GAL3 no compartimento nuclear. Além disso, tanto nas displasias quanto nos carcinomas, a expressão de beta-catenina não membranosa foi alta, indicando que a via de sinalização Wnt também está ativa nos estágios que antecedem a transformação maligna. Por outro lado, nenhuma correlação entre GAL3 nuclear/citoplasmática e beta-catenina membranosa/não membranosa foi alcançada, o que parece sugerir que, em tumores de língua induzidos experimentalmente, a GAL3 pode não ser um importante mediador da via de sinalização Wnt, como contrariamente foi mostrado em tumores de tireoide ${ }^{(40)}$.

É bem aceito que a GAL3 pode ser encontrada em diferentes compartimentos celulares. Além disso, inúmeros trabalhos têm demonstrado que a GAL3 pode mediar várias funções, dependendo de sua localização intracelular ${ }^{(14,21)}$. No citoplasma, a GAL3 atua como molécula antiapoptótica, enquanto no núcleo está associada ao splicing do RNAm, regulação do crescimento celular e ciclo celular ${ }^{(14,16,20,27,36)}$. Paron et al.(27), por exemplo, mostraram que a GAL3 modula e interage no núcleo com o homeodomínio do fator de transcrição da tireoide (TTF-1), um importante fator de transcrição gênica envolvido na proliferação de células tireoidianas. Similarmente, Lin et al. ${ }^{(19)}$ demonstraram que a GAL3 aumenta a expressão de moléculas reguladoras do ciclo celular, como ciclina D1 e de p21 $1^{\text {WaF } 1 / \text { IIP } 1}$. Para nosso conhecimento, esse é o primeiro estudo a avaliar 
quantitativamente a expressão nuclear/citoplasmática de GAL3 em lesões desenvolvidas a partir de um modelo experimental de carcinogênese bucal. Nesse sentido, nós encontramos um predomínio de imunorreatividade citoplasmática em ambas as lesões, em especial nos carcinomas, muito embora nenhum nível de significância tenha sido alcançado. Esse resultado é similar ao observado em carcinoma não pequenas células de pulmão e carcinomas de língua ${ }^{(13,15,30)}$. No estudo de Honjo et al.(15), por exemplo, a positividade nuclear para a GAL3 em carcinomas de língua foi de $4,3 \%$ e a citoplasmática, de $84,9 \%$.

Em um recente estudo publicado por nós, foi observado que, no geral, a imunomarcação para GAL3 nos tumores foi tanto nuclear quanto citoplasmática, sem distinta distribuição em relação a ambos os compartimentos ${ }^{(9)}$. Além disso, nesse estudo, foi possível notar que a intensidade de marcação tumoral foi mais fraca se comparada ao tecido epitelial adjacente não neoplásico. Embora os dados encontrados anteriormente por nós tenham sido um pouco diferentes, é pertinente dizer que isso provavelmente esteja relacionado, primeiro, com a metodologia empregada para a interpretação da imunomarcação de GAL3. Enquanto no presente trabalho foram utilizados critérios quantitativos, com base na contagem de células positivas independente da intensidade da marcação, no trabalho anterior empregou-se um critério semiquantitativo para a interpretação da imunomarcação. Segundo, no atual trabalho foram contados separadamente células com marcação nuclear e citoplasmática para GAL3, enquanto no estudo anterior a análise se baseou em uma descrição geral, subjetiva, da compartimentalização de molécula dentro das células tumorais, sem que nenhum padrão predominante tivesse sido encontrado.

Por outro lado, um aumento estatisticamente significativo de GAL3 nuclear na transição de displasia para carcinoma ( $9 \%$ vs. $15,7 \%$ ) foi observado no presente estudo. Também foi constatado aumento de GAL3 nuclear na transição de displasia para carcinoma na literatura ${ }^{(30,34)}$. Somado a isso, outros trabalhos têm sugerido que a localização intracelular de GAL3 pode indicar transformação maligna e progressão tumoral para determinadas neoplasias ${ }^{(20,21,26,31)}$. No estudo de Puglisi et al.(30), foi encontrada uma associação entre GAL3 nuclear e prognóstico ruim para carcinomas não pequenas células de pulmão. Nesse sentido, é possível predizer que o aumento da expressão de GAL3 nuclear na transição de displasia para carcinoma, como observado nesse estudo, pode indicar um evento inicial no processo de transformação maligna do epitélio lingual provavelmente por meio da ativação da proliferação celular.
Similar a GAL3, a beta-catenina pode estar presente em vários compartimentos celulares, como membrana plasmática e citoplasma/núcleo ${ }^{(32)}$. É bem aceito na literatura que a estabilização seguida de acúmulo de beta-catenina em citoplasma e núcleo ocorre mediante a ativação da via de sinalização $\mathrm{Wnt}^{(5)}$. Além disso, alguns trabalhos têm mostrado que a via de sinalização Wnt é uma importante via reguladora da proliferação celular e está frequentemente alterada em tumores ${ }^{(27)}$. Vários estudos têm mostrado reduzida expressão de beta-catenina membranosa e aumento da expressão citoplasmática em diferentes tumores, incluindo carcinoma epidermoide de boca ${ }^{(22)}$. Similarmente, foi mostrado que a via de sinalização Wnt está alterada em células de carcinoma de cavidade bucal(29). Contudo, há poucas informações na literatura sobre o real papel da via de sinalização Wnt no desenvolvimento e na progressão desses tumores, e os resultados alcançados ainda são contraditórios.

Consistente com isso, um recente estudo mostrou que células positivas para Wnt apresentavam concomitantemente maior expressão de beta-catenina difusamente no citoplasma e no núcleo ${ }^{(38)}$. Em contraste, Kudo et al. ${ }^{(18)}$ observaram baixa expressão de beta-catenina em células de carcinomas epidermoides metastáticos quando comparada com células de tumores não metastáticos. A análise imunohistoquímica no presente estudo mostrou que o índice de positividade para beta-catenina não membranosa foi maior que a membranosa nas displasias e nos carcinomas. Esses achados vão de encontro ao descrito por Sato et al. ${ }^{(33)}$, que observaram expressão de beta-catenina não membranosa em $62 \%$ das lesões displásicas e $50 \%$ dos carcinomas em língua de ratos desafiados com $4 \mathrm{NQO}$.

Por outro lado, em um estudo conduzido em ratos desafiados com $4 \mathrm{NQO}$, foi observada expressão de betacatenina citoplasmática em células de mucosa oral analisadas em diferentes períodos de observação, com nenhuma diferença estatisticamente alcançada, sugerindo que a via de sinalização Wnt não está envolvida no processo de carcinogênese ${ }^{(12)}$. Contrário a isso, nossos resultados sugerem que a via de sinalização Wnt está ativa em ambas as lesões, embora um pouco mais nos carcinomas, e que o acúmulo de beta-catenina não membranosa é um evento inicial no processo de carcinogênese de epitélio lingual. Contudo, outros estudos são necessários para elucidar esse aspecto.

Recentemente foi mostrado que a GAL3 interage com a beta-catenina no citoplasma, auxiliando-a na translocação até o núcleo e na posterior ligação ao sítio promotor do T-cell specific transcription factor/lymphoid enhancer-binding factor-1 
(TCF/LEF-1), culminando com a ativação da transcrição de genes da ciclina D1 e c-Myc ${ }^{(36,38)}$. Com base nisso, procurouse, aqui, correlacionar expressão de GAL3 e beta-catenina em carcinomas com intuito de demonstrar o possível papel dessa lectina na via de sinalização Wnt nessas lesões. Diferentemente do esperado, a análise de correlação entre GAL3 nuclear/ citoplasmática e beta-catenina não membranosa/membranosa não atingiu nível de significância. Esses resultados são diferentes dos encontrados por Weinberger et al.(39), em que se mostrou forte correlação entre GAL3 e beta-catenina não membranosa em amostras de carcinomas de tireoide. Por outro lado, são similares aos encontrados por Ferrazzo et al.(10) em que não se encontrou nenhuma correlação entre betacatenina não membranosa e GAL3 em uma amostra de tumores de glândula salivar. É provável que essas contradições possam estar relacionadas com o tipo de amostra estudada e a metodologia empregada na análise da imuno-histoquímica. Contudo, não se pode descartar que essas diferenças sejam decorrentes da ideia de que a função intracelular de GAL3 é tecido-específica e célula-específica ${ }^{(6,21)}$. Assim, a ausência de correlação entre GAL3 e beta-catenina em nosso estudo sugere que a GAL3 pode não ser uma importante mediadora da via de sinalização Wnt em tumores de língua induzidos experimentalmente.

\section{Agradecimentos}

Os autores agradecem à Fundação de Amparo à Pesquisa do Estado de Minas Gerais (FAPEMIG) pelo apoio financeiro (protocolo $n^{\circ}$ CDS-APQ-00397-09).

\section{Referências}

1. BARNES, L. et al. World Health Organization Classification of Tumours. Pathology and Genetics of Head and Neck Tumors. Lyon, France; IARC Press, 2005.

2. CHIARIOTTI, L. et al. Control of galectin gene expression. Biochimie, v. 81, n. 4, p. 381-8, 1999.

3. COLI, A. et al. Galectin-3, a marker of well-differentiated thyroid carcinoma, is expressed in thyroid nodules with cytological atypia. Histopathology, v. 40, n. 1 , p. 80-7, 2002.

4. CVEJIC, D. et al. Galectin-3 and proliferating cell nuclear antigen (PCNA) expression in papillary thyroid carcinoma. Exp Oncol, v. 27, p. 210-4, 2005.

5. DAA, T. et al. Mutations in components of the Wnt signaling pathway in adenoid cystic carcinoma. Modern Pathol, v. 17, p. 1475-82, 2004.

6. DUMIC, J.; DABELIC, S.; FLOGEL, M. Galectin-3: an open-ended story. Biochim Biophys Acta, v. 1760, p. 616-35, 2006.

7. FARIA, P. R. Carcinogênese bucal induzida pelo 4NQO em língua de camundongos knockout para o gene da galectina-3. Uberaba, 2006. Tese (doutoramento). Universidade Federal do Triângulo Mineiro.

8. FARIA, P. R. et al. Clinical presentation of patients with oral squamous cell carcinoma when first see by dentists or physicians in a teaching hospital in Brazil. Clinical Oral Invest, n. 7, p. 46-51, 2003.

9. FARIA, P. R. et al. Estudo da expressão de galectina-3 em carcinomas de língua de camundongos. J Bras Patol Med Lab, v. 44, n. 3, p. 221-6, 2008.

10. FERRAZZO, K. L. et al. Differential expression of Gal3, beta-catenin and cyclin D1 in adenoid cystic carcinoma and polymorphous low-grade adenocarcinoma of salivary glands. J Oral Pathol Med, v. 38, p. 701-7, 2009.

11. FRACALOSSI, A. C. C. et al. The role of matrix metalloproteinases 2 and 9 during rat tongue carcinogenesis induced by 4-nitroquinoline 1-oxide. J Mol Histol, v. 41, p. 19-22, 2010.

12. FRACALOSSI, A. C. C. et al. Wnt/beta-catenin signalling pathway following rat tongue carcinogenesis induced by 4-nitroquinoline 1-oxide. Exp Mol Pathol, n. 88, v. 1 , p. $176-83,2010$

13. GILLENWATER, A. et al. Expression of galectins in head and neck squamous cell carcinoma. Head Neck, v. 18, p. 422-32, 1996.

14. GONG, H. C. et al. The NH2 terminus of galectin-3 governs cellular compartmentalization and functions in cancer cells. Cancer Res, v. 59, n. 24, p. 6239-45, 1999.

15. HONJO, Y. et al. Expression of cytoplasmic galectin-3 as a prognostic marker in tongue carcinomas. Clin Cancer Res, v. 6, n. 12, p. 4635-40, 2000.

16. INOHARA, H.; AKAHANI, S.; RAZ, A. Galectin-3 stimulates cell proliferation. Exp Cell Res, v. 245, n. 2, p. 294302, 1998.

17. KANOJIA, D.; VAIDYA, M. M. 4-Nitroquinoline-1-oxide induced experimental carcinogenesis. Oral Oncol, v. 42, n. 7, p. 655-67, 2006

18. KUDO, Y. et al. Invasion and metastasis of oral cancer cells require methylation of e-cadherin and/or degradation of membranous beta-catenin. Clin Cancer Res, v. 10, n. 16 , p. $5455-63,2004$

19. LIN, H. M. et al. Galectin-3 mediates genistein-induced $\mathrm{G}(2) / \mathrm{M}$ arrest and inhibits apoptosis. Carcinogenesis, v. 21, n. 11, p. 1941-5, 2000.

20. LIU, F. T. Galectins: a new family of regulators of inflammation. Clin Immunol, v. 97, p. 79-88, 2000.

21. LIU, F. T.; RABINOVICH, G. A. Galectins as modulators of tumour progression. Nat Rev Cancer, v. 5, p. 29-41, 2005.

22. LO MUZIO, L. A possible role for the WNT-1 pathway in oral carcinogenesis. Crit Rev Oral Biol Med, v. 12, p. 152-65, 2001 
23. LOSI-GUEMBAROVSKI, R. et al. Oral carcinoma epidemiology in Paraná State, Southern Brazil. Cad Saúde Pública, v. 25, n. 2, p. 393-400, 2009.

24. LUMERMAN, H.; FREEDMAN, P.; KERPEL, S. Oral epithelial dysplasia and the development of invasive squamous cell carcinoma. Oral Surg Oral Med Oral Pathol Oral Radiol Endod, v. 79, p. 321-9, 1995.

25. NAKAHARA, S.; OKA, N.; RAZ, A. On the role of galectin-3 in cancer progression. Apoptosis, v. 10, p. 267-75, 2005.

26. OCHIENG, J.; FURTAK, V.; LUKYANOV, P. Extracellular functions of galectin-3. Glycoconjugate J, v. 19, n. 7-9, p. 527-35, 2004.

27. PARON, I. et al. Nuclear localization of Galectin-3 in transformed thyroid cells: a role in transcriptional regulation. Biochem Bioph Res Co, v. 302, n. 3, p. 545-53, 2003.

28. PEREIRA, M. C. et al. Hystologic subtypes of oral squamous cell carcinoma: prognostic relevance. J Can Dent Assoc, v. 73, n. 4, 2007.

29. PRADO, S. M. D. et al. Expression of Wnt gene family and frizzled receptors in head and neck squamous cell carcinomas. Virchows Arch, v. 455, p. 67-75, 2009.

30. PUGLISI, F. et al. Galectin-3 expression in non-small cell lung carcinoma. Cancer Lett, v. 212, n. 2, p. 233-9, 2004.
31. RABINOVICH, G. A. et al. Galectins and their ligands: amplifiers, silencers or tuners of the inflammatory response? Trends Immunol, v. 23, n. 6, p. 313-20, 2002.

32. REYA, T.; CLEVERS, H. Wnt signaling in stem cells and cancer. Nature, v. 434, p. 843-50, 2005.

33. SATO, K. et al. Expression of b-catenin in rat oral epithelial dysplasia induced by 4-nitroquinoline 1-oxide. Oral Oncol, v. 38, p. 772 -8, 2002.

34. SAUSSEZ, S. et al. Galectin-3 upregulation during tumor progression in head and neck cancer. Laringoscope, n. 118, v. 8, p. 1583-90, 2008.

35. SHIMURA, T. et al. Galectin-3, a novel binding partner of $\beta$-catenin. Cancer Res, v. 64, p. 6363-7, 2004.

36. SHIMURA, T. et al. Implication of galectin-3 in Wnt signaling. Cancer Res, v. 65, p. 3535-7, 2005.

37. TANG, X. H. et al. Oral cavity and esophageal carcinogenesis modeled in carcinogen-treated mice. Clin Cancer Res, v. 10, n. 1, p. 301-13, 2004.

38. URAGUCHI, M. et al. Activation of Wnt family expression and signaling in squamous cell carcinomas of the oral cavity. J Dent Res, v. 83, p. 327-32, 2004.

39. WEIBERGER, P. M. etal. Association of nuclear, cytoplasmic expression of galectin-3 with beta-catenin/Wnt-pathway activation in thyroid carcinoma. Arch Otolaryngol Head Neck Surg, v. 133, n. 5, p. 503-10, 2007.

40. YOSHII, T. et al. Galectin-3 phosphorylation is required for its anti-apoptotic function and cell cycle arrest. J Biol Chem, v. 277, n. 9, p. 6852-7, 2002. 